\title{
Hydrodynamic manoeuvrability data of a flatfish type AUV
}

\author{
Aage, Christian; Wagner Smitt, Leif
}

Published in:

Proceedings of the Oceans Engineering for Today's Technology and Tomorrow's Preservation

Link to article, DOI:

10.1109/OCEANS.1994.364236

Publication date:

1994

Document Version

Publisher's PDF, also known as Version of record

Link back to DTU Orbit

Citation (APA):

Aage, C., \& Wagner Smitt, L. (1994). Hydrodynamic manoeuvrability data of a flatfish type AUV. In Proceedings of the Oceans Engineering for Today's Technology and Tomorrow's Preservation (Vol. Volume 3, pp. 425-430). IEEE. https://doi.org/10.1109/OCEANS.1994.364236

\section{General rights}

Copyright and moral rights for the publications made accessible in the public portal are retained by the authors and/or other copyright owners and it is a condition of accessing publications that users recognise and abide by the legal requirements associated with these rights.

- Users may download and print one copy of any publication from the public portal for the purpose of private study or research.

- You may not further distribute the material or use it for any profit-making activity or commercial gain

- You may freely distribute the URL identifying the publication in the public portal 


\section{Hydrodynamic Manoeuvrability Data of a Flatfish Type AUV}

\author{
Christian Aage \\ Dept, of Ocean Engineering \\ Technical University of Denmark \\ DK-2800 Lyngby, Denmark
}

\author{
Leif Wagner Smitt \\ Danish Maritime Institute \\ Hjortekærsvej 99 \\ DK-2800 Lyngby, Denmark
}

\begin{abstract}
Hydrodynamic manoeuvrability data of the flatfish type autonomous underwater vehicle (AUV) "MARIUS" are presented. "MARIUS" was developed under the EC MAST Programme as a vehicle for seabed inspection and environmental surveys in coastal waters. The AUV has an overall length of $4.5 \mathrm{~m}$ and is driven by two propellers and four thrusters. The data comprise added mass and inertia coefficients, damping, lift and drag coefficients of the vehicle and its control surfaces, as well as resistance and propulsion characteristics. The hydrodynamic data have been determined by full scale tests, using a towing tank equipped with a Planar Motion Mechanism. A few free-sailing tests have been carried out as well. Application of the data and possible improvements of the shape of the vehicle are discussed.
\end{abstract}

\section{INTRODUCTION}

Accurate hydrodynamic data are essential for the optimum steering and manoeuvring of an autonomous underwater vehicle (AUV). Precise track-keeping and fast obstacle avoidance are important qualities of an AUV. The data necessary to investigate these properties and to program the control system, comprise added mass and inertia coefficients, damping, lift and drag coefficients of the vehicle and its control surfaces, as well as resistance and propulsion characteristics. Very few hydrodynamic data for AUVs have yet been published, probably due to the confidential or proprietary nature of previous AUV projects.

The "MARIUS" (Marine Utility Vehicle System) autonomous underwater vehicle has been developed under the EC MAST Programme as a vessel for seabed inspection and environmental surveys in coastal waters. The project was carried out by partners from Portugal, France and Denmark.

"MARIUS" was designed and constructed in 1991-94. Hydrodynamic tank tests were carried out in January and June 1993, and March 1994. Free-sailing radio controlled tests were performed in November 1993 and May 1994. Free-sailing autonomous tests are planned for late 1994.

In this paper a complete set of hydrodynamic data of the "MARIUS" AUV is presented. The hydrodynamic data have been determined by tests on the full scale vehicle, using the towing tank at the Danish Maritime Institute (DMI), which is equipped with a Planar Motion Mechanism (PMM). The free-sailing tests supplement these measurements.

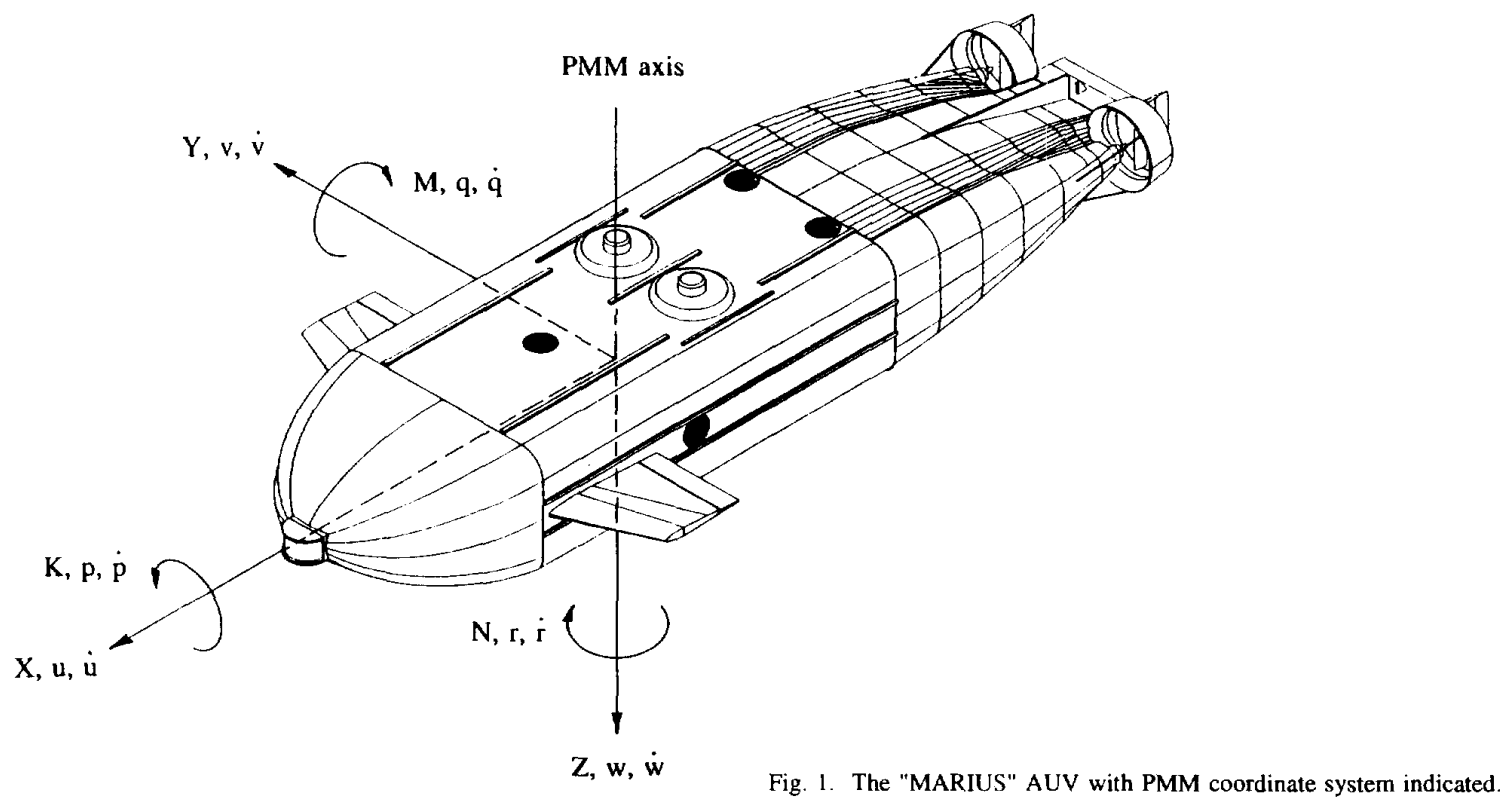




\section{DESIGN OF THE "MARIUS" AUV}

A cylindrical torpedo shape is a common choice for AUVs because of its very low hydrodynamic resistance. For the "MARIUS" a flatfish shape has been chosen because of the requirements for large bottom areas to accomodate the downlooking measuring instruments, including a video camera and a seabed test core sampling apparatus. Furthermore, the flatfish shape facilitates stowage and accessibility of a number of cylindrical pressure vessels, containing batteries, motors, computers, etc. Great care was taken to keep the resistance as low as possible, and a drag coefficient comparable to that of a torpedo was actually obtained.

The need for redundancy in the propulsion system led to a double-propeller system, a little less efficient than the singlepropeller design. The need for protection of the vulnerable propellers led to the adoption of propeller nozzles. The nozzles are actually not advantageous in the cruising mode, but on the other hand they do give a large bollard pull at zero speed, an advantage if the vessel is caught in sea weed.

Manoeuvrability requirements, especially in connection with obstacle avoidance, led to a design with two side rudders behind the propellers, one elevator between the propellers, and two bow diving planes in the form of fixed wings with ailerons. For positioning performance at zero or low speed, the vehicle is equipped with one side thruster and three vertical thrusters through the hull.

The dimensions of the vehicle have been determined by the required space for instruments, computers, motors and batteries, combined with the required diving depth of $600 \mathrm{~m}$ and the required mission range of $50 \mathrm{~km}$ at a speed in the range 2-4 m/s. The main dimensions of the "MARIUS" are presented in Table 1.

Further details of the design and construction of "MARIUS", including the communication and control systems, mission management system, and acoustic collision avoidance system, can be found in [1].

\section{PMM TESTS - THEORETICAL BACKGROUND}

The Planar Motion Mechanism (PMM) technique is used to obtain hydrodynamic coefficients for the equations of motion of the vehicle tested.

The PMM is installed on the towing carriage and via struts and force dynamometers connected to the submerged body (Fig. 2).

During the tests the towing carriage is running at constant speed and except for the towing tests the propellers are operated at the "self propulsion point" giving zero net longitudinal force in steady motion with all control surfaces at zero angle and no drift or pitch angle. The PMM is used either to fix the vessel at a constant yaw or pitch angle, or in the oscillatory mode to generate oscillatory harmonical motions in sway, yaw, heave or pitch.

The resulting forces and moments are measured, and iner-
Table 1. MAIN DIMENSIONS OF THE "MARIUS" AUY

\begin{tabular}{|l|l|r|}
\hline $\mathrm{L}_{\mathrm{PP}}$ & Length from front end to elevator axis & $4.215 \mathrm{~m}$ \\
$\mathrm{~L}_{\mathrm{OA}}$ & Length overall & $4.485 \mathrm{~m}$ \\
$\mathrm{~B}$ & Breadth of hull & $1.100 \mathrm{~m}$ \\
$\mathrm{~B}_{\mathrm{OA}}$ & Breadth incl. bow diving planes & $2.000 \mathrm{~m}$ \\
$\mathrm{D}$ & Depth of hull & $0.600 \mathrm{~m}$ \\
$\mathrm{D}_{\mathrm{OA}}$ & Depth incl. rails and appendages & $0.710 \mathrm{~m}$ \\
$\mathrm{~A}_{\mathrm{F}}$ & Frontal area & $0.650 \mathrm{~m}^{2}$ \\
$\mathrm{~A}_{\mathrm{S}}$ & Side area & $2.400 \mathrm{~m}^{2}$ \\
$\mathrm{~S}$ & Wetted surface & $14.700 \mathrm{~m}^{2}$ \\
$\mathrm{~V}$ & Volume of displacement of outer hull & $2.180 \mathrm{~m}^{3}$ \\
$\mathrm{X}_{\mathrm{PMM}}$ & Elevator axis aft of PMM axis & $2.440 \mathrm{~m}$ \\
$\mathrm{X}_{\mathrm{G}}$ & Centre of gravity aft of PMM axis & $0.220 \mathrm{~m}^{2}$ \\
$\mathrm{I}_{\mathrm{Z}}$ & Mass moment of inertia about PMM axis & $2420 \mathrm{kgm}^{2}$ \\
\hline
\end{tabular}

tial contributions from the body mass and inertia as well as contributions from hydrostatic forces are subtracted to get the pure hydrodynamic forces acting on the body. Both added mass terms and damping terms are identified and expressed in the form of non-dimensional coefficients.

The forces and moments are given in a body-fixed coordinate system with origin where the vertical axis of the PMM intersects the horizontal mid-plane of the vessel (Fig. 1).

A detailed description of the theory of ship manoeuvring and control is given in [2]. The nomenclature used here is in accordance with the SNAME standard [3], which gives the following non-dimensionalizing factors:

$\begin{array}{ll}\text { Forces } & 1 / 2 \rho \mathrm{U}^{2} \mathrm{~L}_{\mathrm{PP}}{ }^{2} \\ \text { Moments } & 1 / 2 \rho \mathrm{U}^{2} \mathrm{~L}_{\mathrm{PP}}{ }^{3} \\ \text { Mass } & 1 / 2 \rho \mathrm{L}_{\mathrm{PP}}{ }_{4} \\ \text { Inertia } & 1 / 2 \rho \mathrm{L}_{\mathrm{PP}} \\ \text { where } & \mathrm{U}=\sqrt{\mathrm{u}^{2}+\mathrm{v}^{2}+\mathrm{w}^{2}}\end{array}$

The non-dimensional motion parameters are:

$$
\begin{aligned}
& \text { Non-diml velocities } \quad\left(\mathrm{u}^{\prime}, \mathrm{v}^{\prime}, \mathrm{w}^{\prime}\right)=\text { vel. } / \mathrm{U} \\
& \text { Non-diml accelerations }\left(\dot{\mathrm{u}}^{\prime}, \dot{\mathrm{v}}^{\prime}, \dot{w}^{\prime}\right)=\text { acc. } \mathrm{L}_{\mathrm{Pp}} / \mathrm{U}^{2} \\
& \text { Non-diml angular vel. } \quad\left(\mathrm{p}^{\prime}, \mathrm{r}^{\prime}, \mathrm{q}^{\prime}\right)=\text { ang. vel. } \mathrm{L}_{\mathrm{PP}} / \mathrm{U} \\
& \text { Non-diml angular acc. }\left(\dot{\mathrm{p}}^{\prime}, \dot{\mathrm{r}}^{\prime}, \dot{\mathrm{q}}^{\prime}\right)=\text { ang. acc. } \mathrm{L}_{\mathrm{PP}}{ }^{2} / \mathrm{U}^{2}
\end{aligned}
$$

The control surface angles $\left(\delta_{\mathrm{R}}, \delta_{\mathrm{E}^{*}} \delta_{\mathrm{A}}\right)$ of rudder, elevator, and aileron, respectively, are measured in radians.

\section{HYDRODYNAMIC TEST PROGRAMME}

During the period January 1993 to May 1994 a total of five test series on the MARIUS vehicle have been carried out:

- Open Water tests on the propeller/nozzle system

- Resistance and Selfpropulsion tests

- Planar Motion Mechanism tests in the horizontal plane

- Planar Motion Mechanism tests in the vertical plane

- Free-sailing tests. 


\section{A. Test Conditions}

The towing tank of the Danish Maritime Institute (DMI) has the dimensions $240 \mathrm{~m} \times 12 \mathrm{~m} \times 5.5 \mathrm{~m}$. For these tests the towing carriage was equipped with an open water propeller dynamometer, and a horizontal as well as a vertical Planar Motion Mechanism (PMM) of DMI's own design.

All tests were carried out with the full scale prototype of the "MARIUS" vehicle. A submergence of $2.0 \mathrm{~m}$ to the center of the vehicle was chosen for all tests, except for the open water tests, where the submergence to the center of the propeller was $0.3 \mathrm{~m}$.

To obtain this submergence in the PMM captive tests the vehicle was mounted on two vertical struts, which were attached to the PMM in the upper end. To minimize the disturbance from the surface-piercing struts on the measurements, the force gauges were mounted inside the vehicle at the lower end of the struts. So even if there was an unavoidable flow disturbance due to the struts, the force measurements were not contaminated by the direct hydrodynamic loads on the struts.

\section{B. Open Water Tests}

The purpose of the open water test is to measure the characteristics of the propeller/nozzle system in undisturbed (open) water. The tests were carried out with the complete propeller, nozzle and side-rudder in place, but with separate measurements of thrust/torque on the propeller and thrust on the nozzle/rudder. The four-bladed propeller was made of two standard model airplane nylon propellers with pitch 0.28 $\mathrm{m}$ and diameter $0.30 \mathrm{~m}$, cut down to a diameter of $0.28 \mathrm{~m}$. The $0.14 \mathrm{~m}$ long custom-made nozzle was of the accelerating type, as used for high propeller loadings.

The open water tests were carried out at propeller rpm's and advance coefficients corresponding to vehicle speeds of $1.5-2.0 \mathrm{~m} / \mathrm{s}$. Further, a number of bollard pull tests and propeller strength tests at overload conditions were made.

The results of the open water tests show that the maximum propeller efficiency in the free-sailing condition is 0.59 , which is a bit low, considering the good aspect ratio and low blade-area ratio of the propeller. The nozzle produces very little thrust in the free-sailing condition.

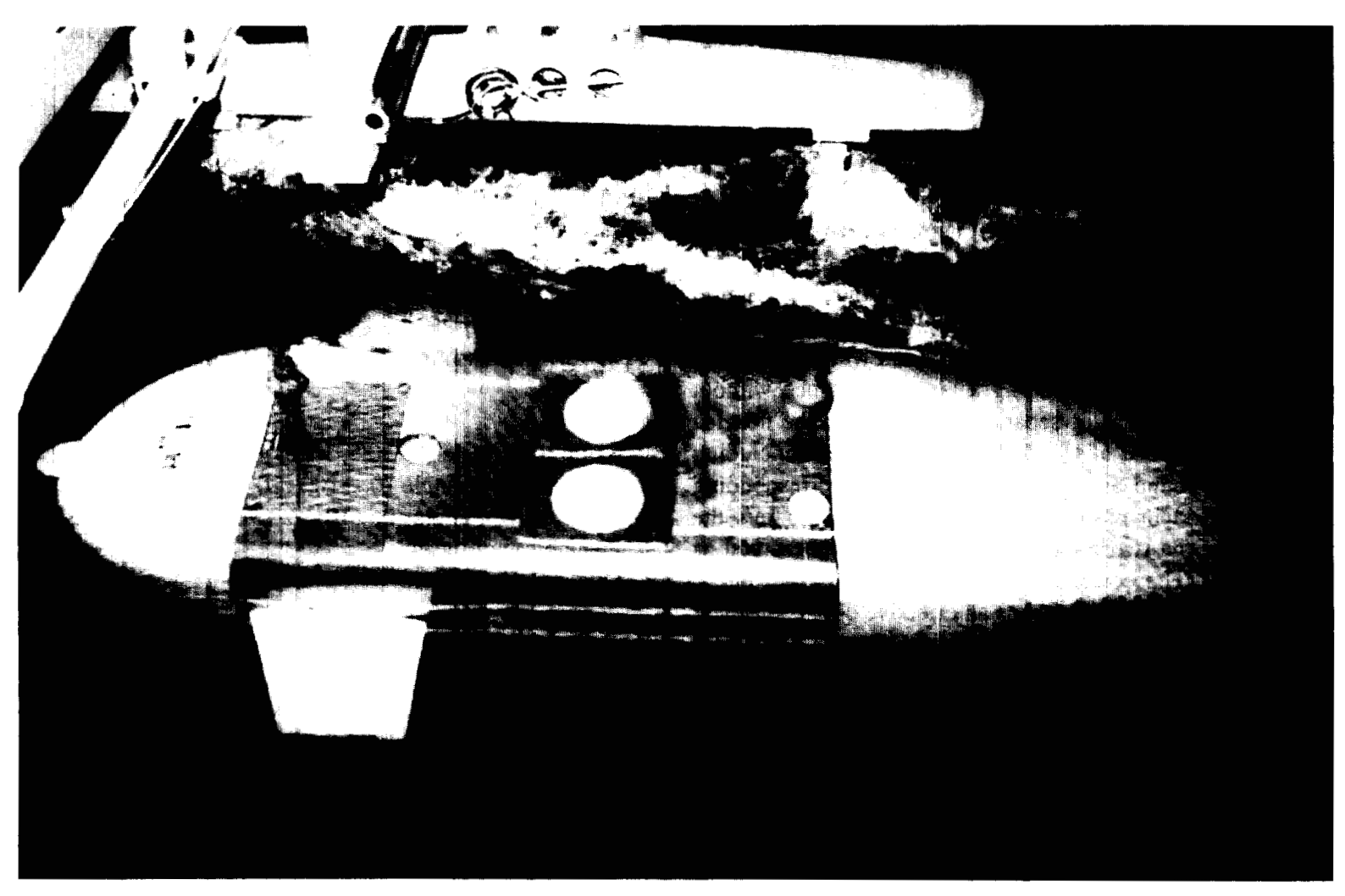

Fig. 2. The "MARIUS" AUV during PMM testing in the horizontal plane. 
In the bollard-pull condition (zero speed of advance) the nozzle proves quite effective, delivering $45 \%$ of the total thrust. The nylon propellers showed no strength problems, even at heavy overload.

\section{Resistance and Selfpropulsion Tests}

The purpose of the resistance test is to measure the resistance of the vehicle without the propulsion system in place. The purpose of the selfpropulsion test is to measure the performance of the propulsion system in the wake of the hull. This raises an interesting definition problem. Whereas the propeller is definitely part of the propulsion system, the nozzle/rudder unit may be considered as either part of the propulsion system or of the hull. In a propulsion context the nozzle is usually considered as part of the propulsion system, but in a manoeuvring context it is more appropriately considered as part of the hull, because it has a large influence on the manoeuvring characteristics, even without the propeller active.

In this test series the resistance and selfpropulsion tests were combined with the horizontal PMM tests (see below), which gave rise to some difficulties. Whereas the propellers could easily be dismantled for the resistance tests, the nozzles and rudder fins could not be dismantled. This meant that the resistance tests had to be carried out with the nozzles in place. To compensate for their resistance, the resistance of nozzles and rudders was measured in open water and deducted from the total resistance. The correction has to take into account the effective speed in place of the nozzles which, due to the wake, is lower than the speed of advance. An estimated wake fraction of $w=0.25$ was applied.

As seen below, a surprisingly large nozzle/rudder resistance was measured. This is due to the fact that, the water flow through the nozzle is significantly different with and without the propeller working, meaning a larger resistance without the propeller, because of separated flow behind the nozzle.

At a vehicle speed of $U=2.0 \mathrm{~m} / \mathrm{s}$ the resistance including nozzles was found as $R_{T}=188 \mathrm{~N}$. At the corresponding effective speed in place of the nozzles $U_{A}=1.5 \mathrm{~m} / \mathrm{s}$ the resistance of the two nozzles and rudders was measured as $R_{N}=55 \mathrm{~N}$. The corrected resistance of the naked hull is hence $R_{0}=133 \mathrm{~N}$, which means an effective drag coefficient $C_{D}=0.10$ based on the frontal area. The drag coefficient going backwards including the nozzles is $C_{D b}=0.23$. For transverse flow the drag coefficient is $C_{D s}=0.65$ based on the side area.

The selfpropulsion tests showed thrust deduction coefficients around $t=0.28$, but with quite large variations. The wvake fraction was found to be close to the estimated $w=$ 0.25 . In a normal selfpropulsion test, high-precision thrust and torque dynamometers are mounted on the propeller shafts. Due to practical constraints this was not possible in the "MARIUS" selfpropulsion tests. Instead the electrical current and voltage of the calibrated drive motors were used as a measurement of the propeller torque and delivered power.

\section{PMM Tests in the Horizontal Plane}

The theory of the PMM testing technique is explained in Section III.

All PMM tests were performed at the speed $U=1.26 \mathrm{~m} / \mathrm{s}$. The propellers were running at the selfpropulsion point during the tests. Longitudinal, transverse and vertical forces were measured together with pitch and yaw moments.

PMM tests in the horizontal plane will give hydrodynamic coefficients related to the sway and yaw motions. In a pure sway test, the vessel is always parallel to the tank centerline while moving in a horizontal sinusoidal course track. In a pure yaw test the vessel is always parallel to the sinusoidal track.

The PMM tests in the horizontal plane comprised the following series:

- Static drift angle $(0, \pm 2.5, \pm 5.0, \pm 7.5, \pm 90,180$ degrees $)$

- Static rudder angle $(0, \pm 10, \pm 20, \pm 30$ degrees $)$

- Static side thruster

- Dynamic pure sway

- Dynamic pure yaw.

\section{E. PMM Tests in the Vertical Plane}

PMM tests in the vertical plane are carried out similarly to those in the horizontal plane. In a pure heave test the vessel is always in a horizontal position while moving in a vertical sinusoidal course track. In a pure pitch test the vessel is always parallel to the vertical sinusoidal track.

The PMM tests in the vertical plane comprised the following series:

- Static trim angle $(0, \pm 0.5, \pm 1.0, \pm 1.5, \pm 2.0$ degrees $)$

- Static elevator angle $(0, \pm 10, \pm 20, \pm 30$ degrees $)$

- Static aileron angle $(0, \pm 10, \pm 20, \pm 25, \pm 30$ degrees $)$

- Dynamic pure heave

- Dynamic pure pitch.

\section{F. Free-sailing Tests}

In addition to the tests in the towing tank of DMI, freesailing tests were carried out in the Copenhagen Harbour in November 1993 and May 1994. Due to radio control problems a systematic free-sailing test programme has not yet been accomplished. However, a few basic manoeuvres using remote radio control by hand have been carried out: turning circles, zig-zag manoeuvres and diving to a few metres below the surface. The results are discussed in Sections $\mathrm{V}$ and VII. 
Table 2. HYDRODYNAMIC COEFFICIENTS FROM HORIZONTAL AND VERTICAL PMM TESTS ON THE "MARIUS" AUV

\begin{tabular}{|c|c|c|c|c|c|c|c|c|c|c|}
\hline \multirow{3}{*}{$\begin{array}{l}\text { Type of Test } \\
\text { Towing Ahead } \\
\text { Towing Astern }\end{array}$} & \multicolumn{10}{|c|}{ Non-dimensional Coefficients, all to be multiplied by $10^{-5}$} \\
\hline & \multicolumn{2}{|c|}{$\mathrm{X}$} & \multicolumn{2}{|r|}{$\mathrm{Y}$} & \multicolumn{2}{|c|}{$\mathrm{Z}$} & \multicolumn{2}{|c|}{$\mathrm{N}$} & \multicolumn{2}{|r|}{$\mathbf{M}$} \\
\hline & $\begin{array}{l}X_{\text {ulul }}^{\prime} \\
X_{\text {ulul }}^{\prime} \\
\end{array}$ & $\begin{array}{l}-534 \\
-844 \\
\end{array}$ & & & & & & & & \\
\hline Static Drift & $X^{\prime}$ & -1400 & $\begin{array}{l}Y^{\prime}{ }^{\prime}{ }^{\prime} \\
Y^{\prime}{ }_{v|v|}\end{array}$ & $\begin{array}{r}-3790 \\
-7300 \\
\end{array}$ & & & $\begin{array}{l}\mathrm{N}^{\prime}{ }^{\prime} \\
\mathrm{N}^{\prime}{ }_{\mathrm{vivl}}\end{array}$ & $\begin{array}{r}-1580 \\
1510 \\
\end{array}$ & & \\
\hline Static Trim & & & & & $\mathrm{Z}_{\mathrm{w}}^{\prime}$ & -24900 & & & $\mathbf{M}_{w}{ }_{w}$ & 6200 \\
\hline Static Rudder & $X_{\delta R \delta R}^{\prime}$ & -1100 & $Y_{\delta R}^{\prime}$ & 1450 & & & $\mathrm{~N}_{\delta \mathrm{R}}^{\prime}$ & -895 & & \\
\hline Static Elevator & & & & & $Z_{\delta E}^{\prime}$ & -842 & & & $\mathbf{M}_{\delta E}^{\prime}$ & -474 \\
\hline Static Aileron & $\mathrm{X}_{\delta \mathrm{A} \delta \mathrm{A}}^{\prime}$ & -1000 & & & $Z_{\delta A}^{\prime}$ & -5190 & & & $\mathrm{M}_{\delta \mathrm{A}}^{\prime}$ & 760 \\
\hline Dynamic Sway & $X^{\prime}$ & -800 & $\begin{array}{l}Y^{\prime}{ }^{\prime} \\
Y_{v|v|}^{\prime} \\
Y_{v i}^{\prime}\end{array}$ & $\begin{array}{r}-3800 \\
-12900 \\
-4450 \\
\end{array}$ & & & $\begin{array}{l}N^{\prime}{ }_{v} \\
N^{\prime}{ }_{v|v|} \\
N^{\prime}{ }_{i}\end{array}$ & $\begin{array}{r}-1410 \\
1940 \\
822 \\
\end{array}$ & & \\
\hline Dynamic Yaw & $X_{\text {rr }}^{\prime}$ & 512 & $\begin{array}{l}Y^{\prime}{ }_{r} \\
Y^{\prime}{ }^{\prime} \\
Y_{i}^{\prime} \\
\end{array}$ & $\begin{array}{r}1330 \\
3570 \\
347 \\
\end{array}$ & & & $\begin{array}{l}N_{r}^{\prime} \\
N_{r m r}^{\prime} \\
N_{r}^{\prime r}\end{array}$ & $\begin{array}{l}-883 \\
-191 \\
-245 \\
\end{array}$ & & \\
\hline Dynamic Heave & & & & & $\begin{array}{l}Z_{{ }_{w}}^{\prime} \\
Z_{\dot{w}}^{\prime} \\
\end{array}$ & $\begin{array}{r}-24500 \\
-11500 \\
\end{array}$ & & & $\begin{array}{l}M_{w}^{\prime} \\
M_{\dot{w}}^{\prime}\end{array}$ & $\begin{array}{r}6450 \\
-1730 \\
\end{array}$ \\
\hline Dynamic Pitch & & & & & $\begin{array}{l}Z^{\prime} \\
Z_{\dot{q}}^{\prime}\end{array}$ & $\begin{array}{r}7960 \\
-1490 \\
\end{array}$ & & & $\begin{array}{l}M_{q}^{\prime} \\
M_{\dot{q}}^{\prime}\end{array}$ & $\begin{array}{r}-2400 \\
-420 \\
\end{array}$ \\
\hline Mass & m' & 5820 & & & & & & & & \\
\hline Inertia & & & $I_{Y}^{\prime}$ & 360 & $\mathrm{I}_{\mathrm{Z}}$ & 364 & & & & \\
\hline Centre of Gravity & $x_{G}^{\prime}$ & -5220 & $y_{G}^{\prime}$ & 0 & $\mathrm{z}_{G}^{\prime}$ & 5000 & & & & \\
\hline
\end{tabular}

\section{RESULTS}

The results of the PMM tests are presented in Table 2 in the form of dimensionless coefficients as indicated by an apostrophe. The coefficients are based on the factors given in Section III. Derivatives have been calculated with respect to the variables indicated by subscripts.

The derivatives have been found on the basis of faired time series of the measured forces and moments. A typical example of an original and a faired time series is shown in Fig. 3.

The resistance and selfpropulsion tests showed that the resistance is lower than expected, probably due to the elliptical front and the carefully streamlined afterbody. The nozzles are not advantageous from a propulsion point of view, but do give a very good bollard pull and mechanical protection to the propellers.

The free-sailing tests performed can only be evaluated intuitively, as feed-back from the instruments in the vessel could not be obtained. However, it was the impression that the "MARIUS" AUV as tested was course unstable both in the horizontal and in the vertical plane. However, the vessel was still controllable, although constant rudder action was necessary to keep it on a straight course.

\section{APPLICATION OF RESULTS}

The "MARIUS" vehicle will be fitted with an advanced controller for steering and manoeuvring in both the horizontal and the vertical plane.

The hydrodynamic coefficients from the PMM tests are being used for simulation studies of the manoeuvring response, with a view to optimizing the controllers for the various tasks the vehicle is planned to perform, such as following a pre-programmed track, flying at constant height over the seabed, avoiding an obstacle detected by the acoustic obstacle avoidance system, or hovering over a specific spot taking current and wave motion into account.

The simulation studies have also included the effect of modifications to the vehicle, e.g. adding fin areas aft for 

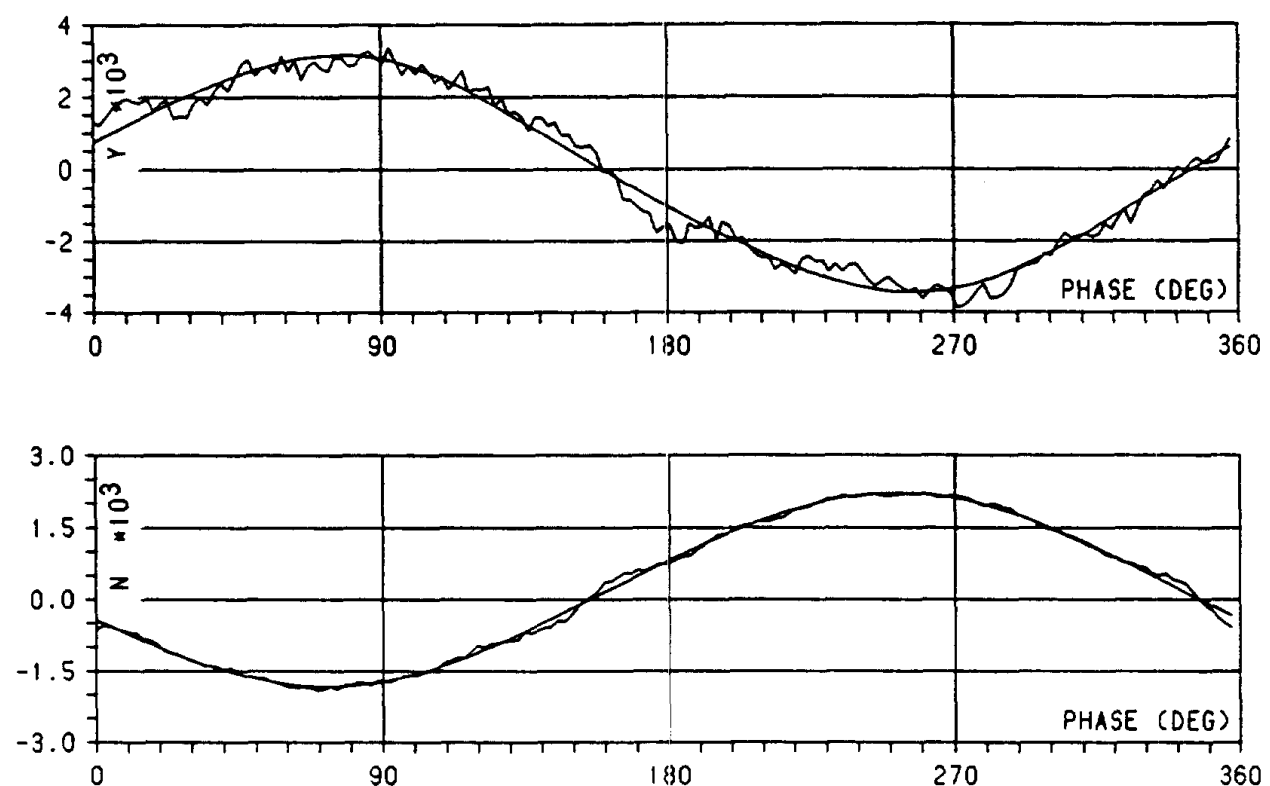

Fig. 3. Typical PMM experimental and faired hydrodynamic forces and moments. The experimental curves are the mean of five PMM oscillations.

improved course stability. The course stability, or more correctly the "controls fixed course stability", may be assessed qualitatively from relatively simple considerations, see [2].

The simulations and the more simple stability coefficients show that the vehicle as tested is course unstable - as are nany surface vessels - and the controllers must be designed with this in mind.

\section{DISCUSSION}

The simulations based on the measured hydrodynamic manoeuvrability data showed that the "MARIUS" was unstable in the horizontal as well as the vertical planes, more pronounced in the horizontal plane. However, new simulations showed that relatively small fins with an area of about $0.08 \mathrm{~m}^{2}$ placed in the aft end of the vessel would be enough to make it stable.

The results of the simulations, the instability as well as the manoeuvrability, were qualitatively confirmed by the freesailing tests.

The authors wish to underline that, steering instability does not mean that the vessel cannot be controlled. An unstable ship is actually highly manoeuvrable, and in some cases a certain degree of instability is even desirable. However, instability requires constant rudder action to keep the vessel on a straight course. This again causes power consumption and added resistance of the vessel. With a good controller this power loss can be made negligible.

Further simulations and free-sailing tests will determine the optimum degree of course stability for the "MARIUS".

\section{ACKNOWLEDGMENTS}

The authors would like to thank all the partners of the EC MAST "MARIUS" Programme for their cooperation and for the permission to publish the results of these PMM tests.

Special thanks are due to Mr. Axel Mølgaard of DMI for his excellent work during the PMM testing and analysis.

\section{REFERENCES}

[1] Egeskov, P.; Bjerrum, A.; Pascoal, A.; Silvestre, C.; Aage, C. \& Wagner Smitt, L.: "Design, Construction and Hydrodynamic Testing of the AUV MARIUS", Proceedings of the AUV'94 Symposium on Autonomous Underwater Vehicle Technology, IEEE Oceanic Engineering Society, Cambridge, Massachusetts, U.S.A., July 1994, 9 pp.

[2] Lewis, E.V. (editor): "Principles of Naval Architecture", The Society of Naval Architects and Marine Engineers, Jersey City, New Jersey, U.S.A., Second Revision, 1988, Volume III, Chapter IX, pp. 191-422.

[3] SNAME: "Nomenclature for Treating the Motion of a Submerged Body Through a Fluid", SNAME Technical and Research Bulletin 1-5, The Society of Naval Architects and Marine Engineers, Jersey City, New Jersey, U.S.A., 1952. 